\title{
Adsorption of Heavy Metals from Small-Scale Gold Processing in Baguio Mining District, Philippines
}

Jyra Rancel Banta

Saint Louis University

Marcelino Jr Lunag ( $\nabla$ mnlunagjr@slu.edu.ph )

Saint Louis University https://orcid.org/0000-0002-4073-2850

Research Article

Keywords: zeolite, bentonite, column, adsorption, lead, small-scale min

Posted Date: February 8th, 2022

DOI: https://doi.org/10.21203/rs.3.rs-1270997/v1

License: (c) (1) This work is licensed under a Creative Commons Attribution 4.0 International License. Read Full License 


\section{Abstract}

Small-scale mining in the Philippines lacks research and technologies for the application of an inexpensive and environmentally sound treatment of its wastewaters. Hence, laboratory-scale fixed-bed column tests were carried out to test and evaluate the sorbent adsorption performance of the Philippine Natural Bentonite (PNB) and the Philippine Natural Zeolite (PNZ) against the heavy metals present in the ball mill facilities within the Baguio Mining District. Results showed that removal percentages of PNB and PNZ in terms of lead (Pb) concentrations are $50.43 \%$ and $26.90 \%$, respectively. Moreover, the dynamic uptake capacity and maximum adsorption capacity values of PNB showed greater values than PNZ and the sorption models, Bohart-Adams, Wolborska, Thomas, and Yoon-Nelson models, which displayed a good fit for the breakthrough curves. Furthermore, the effect of varied flow rate and bed height manifested that an increase in flow rate yields a lesser saturation time while the rise in bed height increases uptake capacity, saturation time, and removal percentage of the system. Regarding the cost-efficiencies of the sorbents, the study revealed that PNB is more cost-efficient than PNZ since only 1.13 Philippine pesos of PNB is required to remove a gram of Pb compared to PNZ, which cost 3.30 pesos. Therefore, this research concluded that PNB could be a better sorbent of $\mathrm{Pb}$ in terms of removal percentage and cost-efficiency. The study recommends more regeneration studies for the reusability of the sorbents after exhaustion and hopes that this research will be a springboard for further environmental studies.

\section{Introduction}

The Philippines is a significant gold producer which ranks 24th in gold production in 2018 (Rashotte 2019). The majority of the gold production is in the five well-known gold mining districts, namely the districts of Baguio and Paracale, which is located on the island of Luzon, while the remaining three: Masara, Surigao, and Masbate, are situated in the Mindanao islands. These mining locations comprise more than $60 \%$ of gold produced, all of which are small-scale mining operations (Simeon 2019). The Republic Act 7076, also known as the People's Small-scale Mining Act of 1991, has allowed these small-scale mines (SSM) to be operated in areas declared by the law as "Minahang Bayan or Peoples small-scale mining area." Although lawfully recognized, a great majority of SSM operations have been running illegally for decades, wherein licenses are only temporary permits that are valid for less than a year. Most of the miners practice their gold extraction processes using harmful chemicals such as mercury and cyanide due to their high gold recovery and low-cost characteristics. With these, there is an unregulated and widespread small-scale mining operation that dumps untreated toxic wastewater directly into the environment (Mendoza 2014).

The non-compliance of SSM operators to environmental laws and regulations is one of the main reasons the approval rate of permits is very low and the biggest obstacle in obtaining an Environmental Compliance Certificate (ECC) (Simeon 2019). In small-scale mines, the waste disposal system is one of the major issues impeding the approval of the eleven applications for SSM permits in Tuba, Benguet. The study of Macasieb et al. (2014) detected traces of heavy metals such as arsenic (As), mercury $(\mathrm{Hg})$, and lead $(\mathrm{Pb})$ in the sediments of Bued River, which primarily covers the provinces of Benguet, Pangasinan, and La Union. Despite the consequences of improper wastewater disposal, which causes pollution to the Bued river and its tributaries, small-scale miners continue their gold processing operations. The need for intervention for this kind of undertakings is paramount for environmental protection.

Over the years, numerous treatment processes were developed to remove heavy metals from polluted waters. These include reverse osmosis, ultrafiltration, ion exchange, and electrodialysis; however, these technologies are costly, which most SSM industries cannot afford. One of the least expensive methods is adsorption, which depends on the sorbent material used (Acheampong et al., 2010), such as the naturally occurring clay minerals and zeolite. These minerals have small particle sizes and are mainly composed of silica, alumina, water, and weathered rocks. The adsorption capabilities of clay minerals and zeolite are owed to their complex porous structures and high specific surface area, allowing physical solid and chemical attractions with species dissolved in solutions such as heavy metals (Uddin 2017).

The Philippines is known to bear mineralization of clay minerals zeolite and bentonite, which are found to adsorb heavy metals such as the study of Gili et al. (2019). Zeolite and bentonite are locally found in regions of Pangasinan (Region I), and Albay (Bicol) (PSA 2013). The Philippine natural bentonite (PNB) is predominantly composed of mordenite, hectorite, and montmorillonite with kaolinite, feldspar, mica, and nontronite traces. It is chemically composed of $47.9 \% \mathrm{SiO}_{2}$ and $14.02 \% \mathrm{Al}_{2} \mathrm{O}_{3}$ (Olegario and Gili 2021). On the other hand, the Philippine natural zeolite (PNZ) comprised of mordenite followed by clinoptilolite and chabazite has a chemical composition of PNZ is $73.20 \%$ silica and $10.72 \%$ alumina, with a calculated $\mathrm{Si} / \mathrm{Al}$ ratio of 3.67 , which is higher than the Si/Al ratio of PNB (Olegario-Sanchez and Pelicano 2017). According to literature, these adsorption materials, specifically the use of natural zeolite and bentonite, have not been fully employed in the Philippine Small-Scale Mining operations. Hence, this study aims to evaluate the adsorption capability or removal efficiency and cost-effectiveness of natural zeolite and bentonite as an alternative wastewater treatment method to remove heavy metals found in SSM wastewater so that the Minahang Bayan or the so-called small-scale mining areas will have a higher approval rate due to its improved wastewater treatment method.

\section{Materials And Methods}

\subsection{Study Area and Wastewater Sampling}

The study was conducted in Barangay Loacan, Itogon, Benguet among the SSM processing facilities under Loacan, Itogon Pocket Miners Association (LIPMA) since the area is declared as a Minahang Bayan in 2019. However, the facilities still practice direct dumping untreated wastewater into the environment. Nevertheless, wastewater samples were collected from the five disposal points along with the ball mills of the LIPMA area. A total of $10 \mathrm{~L}$ wastewater discharge was collected from a full 24 hour-operation, not including cleaning activities and downtime. The water samples were then characterized using X-ray Fluorescence (XRF) Vanta M Series. According to Zhou et al. (2018), the XRF device is an effective alternative and portable method of analyzing polluted waters caused by heavy metals. 


\subsection{Preparation of Sorbents}

The PNB and PNZ materials were acquired from LITHOS Manufacturing, which was then ground with a ceramic mortar and pestle and sieved to 0.25-0.40 $\mathrm{mm}$ particles using stainless steel test sieves. No further treatment was applied to maintain the as-purchased properties of the sorbent's materials. The samples of the PNB and PNZ were again analyzed for their chemical composition using the Vanta M Series XRF Analyzer in the Department of Chemical and Mining Engineering, Saint Louis University, Baguio City. The water sample and sorbents were measured in analyzed in triplicate analysis.

\subsection{Experimental Set-up}

Adsorption was studied by employing a laboratory scale fixed-bed column setup for natural zeolite and natural bentonite, as shown in Fig. 1. A fixed-bed column setup is preferred because the effect of operational parameters such as the amount of sorbent and feed flow rate may be investigated, compared to batch sorption tests that only analyze a sorbent's adsorption capacity (Sazali et al. 2020). A standard borosilicate glass chromatography column of $11 \mathrm{~mm}$ inner diameter and $200 \mathrm{~mm}$ high was used to house the media sorbent. The bottom of the column includes a sintered glass disk to support the adsorbent bed and minimize the loss of adsorbent mass. A slurry of the sorbents was then added into the glass column to achieve uniform packing. The stationary phase (sorbent) was allowed to settle up to a specific depth. Then, the mobile phase (solvent) will be drained only up to the level of the stationary phase to avoid displacement of the packed sorbent when the feed water comes into the system. A peristaltic dosing pump with an adjustable flow rate was used to maintain the desired feed flow rate. The experiment was held at room temperature $22^{\circ} \mathrm{C}-23^{\circ} \mathrm{C}$.

The effects of the process parameters were studied by varying the sorbents bed's depth and the system's feed flow rate. The samples were collected at regular intervals from the outlet of the column. After that, the concentration of the samples was analyzed using the XRF Analyzer. The varied operational parameters per column setup are shown in Table 1.

Table 1

Operational parameter per column setup

\begin{tabular}{|lll|}
\hline Sorbent & Bed height $(\mathrm{mm})$ & Feed flow rate $\left(\mathrm{mL} \cdot \mathrm{min}^{-1}\right)$ \\
\hline PNZ & 10 & 1 \\
PNZ & 15 & 1 \\
PNZ & 20 & 1 \\
PNZ & 10 & 3 \\
PNB & 10 & 1 \\
PNB & 15 & 1 \\
PNB & 20 & 1 \\
PNB & 10 & 3 \\
\hline
\end{tabular}

\subsection{Data processing and analysis}

The performance of each column setup with varied sorbent type, amount, and the feed flow rate was determined by plotting the breakthrough curves for $\mathrm{Pb}$ adsorption. The dimensionless concentration of $\mathrm{C} / \mathrm{C}_{\mathrm{o}}$ is plotted against time, where $\mathrm{C}$ is the effluent concentration at any time $t$, and $\mathrm{C}_{\mathrm{o}}$ is the feed concentration. The total adsorbed species, $\mathrm{q}_{\mathrm{total}}$ in $\mathrm{mg}$, is calculated as the area above the breakthrough curve times the feed flow rate as shown in equation one below adapted from Karimi et al. (2012):

$$
q_{\text {total }}=\frac{Q}{100} \int_{0}^{t_{\text {total }}}\left(C_{o}-C\right) d t
$$

Where $\mathrm{Q}$ is the volumetric flow rate $\left(\mathrm{mL} \cdot \mathrm{min}^{-1}\right),\left(\mathrm{C}_{\mathrm{o}}-\mathrm{C}\right)$ is the adsorbed metal concentration represented by the equation of the breakthrough curve ( $\left.\mathrm{mg} / \mathrm{L}\right)$, and $t$ is the total time of flow (min).

The dynamic uptake capacity of the columns at exhaustion point is calculated from equation two based on the study of Chittoo and Sutherland (2020):

$$
q_{e}=\frac{q_{\text {total }}}{m}
$$


Where $\mathrm{q}_{\mathrm{e}}$ is the mass of adsorbate adsorbed per mass of adsorbent at equilibrium $\left(\mathrm{mg} \cdot \mathrm{g}^{-1}\right)$ and $\mathrm{m}$ is the mass of adsorbent packed in the column, $\mathrm{g}$.

The total removal percentage of metal was calculated from the following equation 3 below:

$$
R_{E}(\%)=\frac{q_{\text {total }}}{m_{\text {total }}} \times 100
$$

3

Where $\mathrm{m}_{\text {total }}(\mathrm{mg})$ is the total amount of metal entering the column at $\mathrm{t}_{\text {total }}$, which is calculated by the following equation 4 (Karimi et al. 2012 ):

$$
m_{\text {total }}=\frac{C_{o} Q t_{\text {total }}}{1000}
$$

4

The simulation of an adsorption column was achieved by fitting the experimental data into empirical sorption models as specified below and by calculating corresponding model parameters. The determined parameters are used to predict the adsorption performance given new operational conditions to facilitate the up-scale design of column systems.

\section{Bohart-Adams Model}

The Bohart-Adams model was based on the assumption that the adsorption rate is proportionate to the adsorbate initial concentration and the remaining capacity of the adsorbent (Bohart and Adams 1920). The model was used to describe the portion of the breakthrough curve where $C / C_{0}$ is less than $50 \%$. The Adams-Bohart model is expressed as:

$$
\frac{C}{C_{o}}=e\left(k_{A B} C_{o} t-k_{A B} N_{o} \frac{Z}{u}\right)
$$

Where $\mathrm{k}_{\mathrm{AB}}$ is the Bohart-Adams constant $\left(\mathrm{L} \cdot \mathrm{mg}^{-1} \cdot \mathrm{min}^{-1}\right), \mathrm{Z}$ is the bed height $(\mathrm{cm}), \mathrm{u}$ is the linear flow rate $(\mathrm{cm} / \mathrm{min})$, and $\mathrm{N}_{\mathrm{o}}$ is the volumetric adsorption capacity (mg. $\mathrm{L}^{-1}$ ) (Zhang et al. 2019). The $\mathrm{k}_{\mathrm{AB}}$ and $\mathrm{N}_{\mathrm{O}}$ are empirical constants of the Bohart-Adams model, which values are characteristics of a specific column system. These constants are applied in scale-up studies wherein the desired column system is reproduced into a larger column.

\section{Wolborska Model}

The Wolborska model was a mathematical model that illustrates the lower concentration region of the breakthrough curve (Wolborska 1989). The model is established on the general equation of mass transfer accounting for the diffusion mechanism of the breakthrough curve (Trgo et al., 2011). It is expressed as:

$$
\frac{C}{C_{o}}=e\left(\frac{\beta C_{o} t}{N_{o}}-\frac{\beta Z}{u}\right)
$$

Where $\beta$ is the kinetic coefficient of external mass transfer, $\min ^{-1}$ (Chittoo and Sutherland 2020), similar to the Bohart-Adams constant, $\beta$ is a constant empirical characteristic of a specific Wolborska model of a particular column system. Also, it is applicable in scaling up laboratory-scale columns.

\section{Thomas Model}

The Thomas model was used to estimate the maximum adsorption capacity of a system based on the mass-transfer theory (Thomas, 1948). It was established to represent adsorption without the consequences of intraparticle mass transfer resistance and external film resistance. The model assumes that the adsorption rate depends on the surface interaction between the adsorbate and the unused adsorbent capacity (Chittoo and Sutherland 2020). The model is expressed as: 


$$
\frac{C}{C_{o}}=\frac{1}{1+e^{\frac{k_{T H}}{Q}}\left(q_{o} m-C_{o} V\right)}
$$

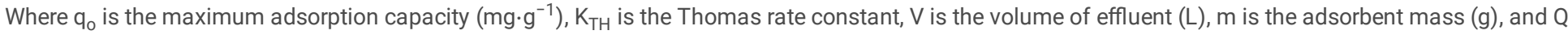
is the feed flow rate $\left(\mathrm{L} \cdot \mathrm{min}^{-1}\right)$ (Zhang et al. 2019).

Yoon-Nelson Model

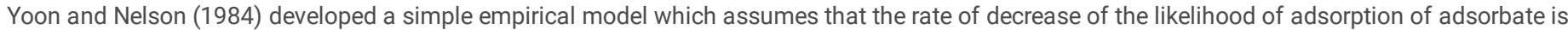
proportionate to the probability of adsorption and breakthrough of an adsorbate and is expressed as:

$$
\frac{C}{C_{o}}-C=e^{\left(K_{Y N} t-K_{Y N} \tau\right)}
$$

Where $\mathrm{k}_{\mathrm{YN}}$ is the Yoon-Nelson rate constant $\left(\mathrm{min}^{-1}\right)$ and $\mathrm{\tau}$ is the time at $\mathrm{C} / \mathrm{C}_{\mathrm{O}}=50 \%(\mathrm{Chittoo}$ and Sutherland 2020$)$.

\section{Results And Discussion}

\subsection{PNB and PNZ Characterization}

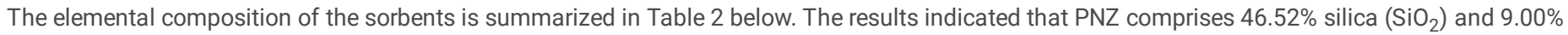

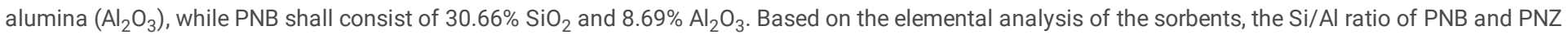

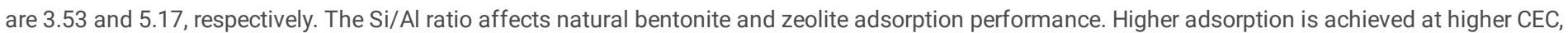

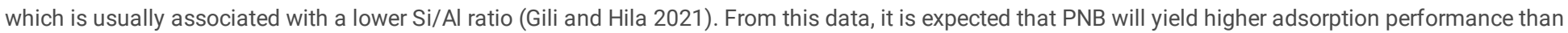

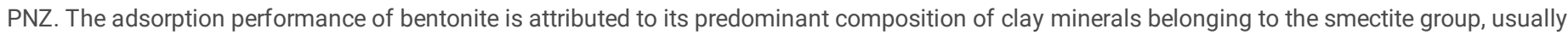

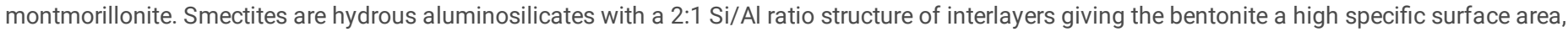

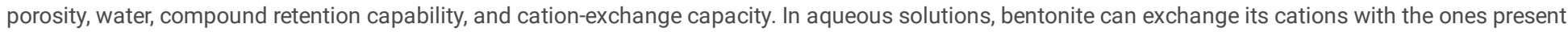
in the solution (Belbachir \& Makhoukhi, 2017). 
Table 2

Elemental composition of PNZ and PNB

\begin{tabular}{|c|c|c|c|}
\hline PNZ & & PNB & \\
\hline Element & Concentration (\%) & Element & Concentration (\%) \\
\hline LE & 73.055 & LE & 77.28 \\
\hline $\mathrm{Si}$ & 15.505 & $\mathrm{Si}$ & 10.22 \\
\hline $\mathrm{Fe}$ & 4.273 & $\mathrm{Fe}$ & 7.77 \\
\hline $\mathrm{Al}$ & 3.615 & Al & 3.475 \\
\hline $\mathrm{Ca}$ & 2.621 & $\mathrm{Ca}$ & 0.5445 \\
\hline $\mathrm{K}$ & 0.3535 & $\mathrm{Ti}$ & 0.474 \\
\hline $\mathrm{Ti}$ & 0.341 & Mn & 0.0914 \\
\hline $\mathrm{Mn}$ & 0.16 & $\mathbf{P}$ & 0.036 \\
\hline $\mathrm{Sr}$ & 0.02525 & $\mathrm{Cu}$ & 0.01675 \\
\hline $\mathrm{Zr}$ & 0.0091 & $\mathrm{Zn}$ & 0.0155 \\
\hline $\mathrm{Zn}$ & 0.009 & $\mathrm{Sr}$ & 0.0147 \\
\hline $\mathrm{Cu}$ & 0.0078 & $\mathbf{N i}$ & 0.0099 \\
\hline $\mathrm{Y}$ & 0.0033 & $\mathrm{Zr}$ & 0.0077 \\
\hline $\mathrm{Ni}$ & 0.0033 & V & 0.0067 \\
\hline Th & 0.0031 & $Y$ & 0.0051 \\
\hline Mo & 0.0021 & Th & 0.0033 \\
\hline $\mathrm{Nb}$ & 0.00135 & $\mathrm{Nb}$ & 0.00245 \\
\hline $\mathrm{Rb}$ & 0.0013 & Mo & 0.00255 \\
\hline $\mathrm{Pb}$ & 0.00125 & $\mathrm{Rb}$ & 0.0004 \\
\hline V & ND & $\mathrm{K}$ & ND \\
\hline $\mathrm{P}$ & ND & $\mathrm{Pb}$ & ND \\
\hline
\end{tabular}

On the other hand, Zeolite is characterized as a crystalline tectosilicate structure interconnected with tetrahedra of silicon, aluminum, and oxygen atoms. The bonding of the tetrahedra to ordinary oxygen atoms prevents dense packing of the layers, leaving open pores or cavities in its framework. The open cavities in zeolite are often occupied by $\mathrm{H}_{2} \mathrm{O}$ molecules and cations commonly exchangeable (Ramesh and Reddy, 2011). The isomorphous substitution between the $\mathrm{Si}^{4+}$ and $\mathrm{Al}^{3+}$ ions in bentonite and zeolite crystal lattices results in a negative net charge. This negative charge is neutralized by the exchangeable cations such as $\mathrm{Na}^{+}, \mathrm{K}^{+}$, and $\mathrm{Ca}^{2+}$. These cations can be exchanged with heavy metal ions during adsorption. The released ions from the trading of cations in the bentonite and zeolite adsorption are relatively safe, which is advantageous in choosing these materials in wastewater treatment for heavy metals (OlegarioSanchez and Pelicano, 2017).

\subsection{Wastewater Characterization}

The heavy metal concentration of the wastewater composite is composed mainly of lead, cadmium, and iron, as shown in Table 3 . Results showed that mercury $(\mathrm{Hg})$ and arsenic (As) were below the limits of detection of the Vanta M Series XRF Analyzer. In contrast, a high amount of Pb, Cd, and Fe were detected, exceeding the Class D standard set by DAO 2016-08 (DENR 2016). Hence, the wastewater quality of the samples indeed contained harmful heavy metals, which need to be treated.

Table 3

Wastewater concentration and standard limits

\begin{tabular}{|llllll|}
\hline & $\mathrm{Pb}(\mathrm{ppm})$ & $\mathrm{Cd}(\mathrm{ppm})$ & $\mathrm{Fe}(\mathrm{ppm})$ & $\mathrm{Hg}(\mathrm{ppm})$ & As (ppm) \\
\hline Ave Concentration & 82.8 & 19 & 432.4 & $\mathrm{ND}$ & $\mathrm{ND}$ \\
Effluent Standard (Class D) & $<0.2$ & $<0.02$ & $<35$ & $<0.008$ & $<0.08$ \\
\hline
\end{tabular}

\subsection{Removal efficiency}


The performance of each column setup, with varied sorbent type, sorbent amount, and feed flow rate, were determined by plotting the breakthrough curves for $\mathrm{Pb}$ adsorption as shown in Fig. 2. Results showed that the removal percentage values between natural zeolite and natural bentonite are $26.90 \%$ and $50.43 \%$, respectively, as shown in the statistical hypothesis testing for the difference of two means for independent groups in Table 5 . The degrees of freedom are calculated using a 2-sample t-test with unequal variances (Welch's t-test). The test shows a significant difference with a p-value of 0.02518 $(p<0.05)$ in the removal percentage between PNB and PNZ as sorbent for Pb. These results suggest that the mean removal percentage of PNB is greater than that of PNZ.

On the other hand, the total adsorbed species are presented in Table 4, in which the breakthrough curves do not follow a smooth curve. In terms of total adsorbed species, $\mathrm{q}_{\mathrm{total}}$, the adsorption of each setup shows that PNB yields higher performance than PNZ. As determined in the Si/Al ratio calculation, PNB indeed showed a higher experimental adsorption performance based on the removal percentage owing to its lower $\mathrm{Si} / \mathrm{Al}$ ratio, consequently a higher $\mathrm{CEC}$, as compared to PNZ.

Table 4

Breakthrough parameters

\begin{tabular}{|c|c|c|c|c|c|c|c|c|}
\hline Sorbent & $\mathrm{BH}(\mathrm{mm})$ & $\mathrm{FR}\left(\mathrm{mL} \cdot \mathrm{min}^{-1}\right)$ & Area & $\mathrm{q}_{\mathrm{total}}(\mathrm{mg}, \mathrm{Pb})$ & $\mathrm{m}(\mathrm{g})$ & $\begin{array}{l}\mathrm{q}_{\mathrm{e}} \\
\text { (mg Pb/g sorbent) }\end{array}$ & $t_{\text {total }}(0.9)$ & $\mathrm{m}_{\text {total }}(\mathrm{mg} \mathrm{Pb})$ \\
\hline PNB & 10 & 3 & 82.37 & 20.46 & 0.41 & 49.90 & 178.08 & 44.24 \\
\hline PNZ & 10 & 3 & 42.03 & 10.44 & 0.73 & 14.30 & 210.4 & 52.26 \\
\hline PNB & 10 & 1 & 74.28 & 6.15 & 0.41 & 15.00 & 226.08 & 18.72 \\
\hline PNZ & 10 & 1 & 51.69 & 4.28 & 0.73 & 5.86 & 254.08 & 21.04 \\
\hline PNB & 15 & 1 & 195.08 & 16.15 & 0.61 & 26.48 & 336.22 & 27.84 \\
\hline PNZ & 15 & 1 & 114.13 & 9.45 & 1.09 & 8.67 & 376.6 & 31.18 \\
\hline PNB & 20 & 1 & 326.08 & 27.00 & 0.82 & 32.93 & 504.77 & 41.79 \\
\hline PNZ & 20 & 1 & 195.65 & 16.2 & 1.45 & 11.17 & 529.2 & 43.82 \\
\hline
\end{tabular}

Table 5. Comparison of Mean Removal Percentage

\begin{tabular}{ccc}
\hline & $\mathrm{R}_{\mathrm{E} \text { PNB }}$ & $\mathrm{R}_{\mathrm{E} \text { PNZ }}$ \\
\hline$\overline{\boldsymbol{x}}$ & 50.43 & 26.90 \\
\hline $\mathbf{s d}$ & 13.96 & 8.25 \\
\hline $\mathbf{d f}$ & $4.87 \approx 5$ \\
\hline$\alpha$ & 0.05 \\
\hline $\mathrm{t}_{5,0.025}$ & \multicolumn{2}{c}{2.57} \\
\hline
\end{tabular}

\subsection{Application of Fixed Bed Adsorption Models}

Linear models were initially obtained as a prerequisite of the non-linear models. Logarithms were used to linearize the experimental data to estimate characteristic parameters of the different adsorption models. The experimental data were fitted into the Bohart-Adams and Wolborska models for adsorption. Characteristic parameters were estimated by linear models $\ln \left(\mathrm{C} / \mathrm{C}_{0}\right)$ versus $\mathrm{t}$ in regions where the relative concentration $\mathrm{C} / \mathrm{C}_{0}<0.75$ at $\mathrm{Q}=1$ $\mathrm{mL} \cdot \mathrm{min}^{-1}$. The respective values of parameters $\mathrm{K}_{A B}, \mathrm{~N}_{0}$, and $\beta_{\mathrm{a}}$ are shown in Table 6, wherein the parameters $\mathrm{K}_{A B}$ and $\beta_{\mathrm{a}}$ increase with decreasing bed height while the $N_{0}$ values increase with increasing bed height. In general, $K_{A B}$ and $\beta_{a}$ values are greater in PNB than in PNZ, whereas $N_{0}$ values are greater in PNZ than in PNB. 
Table 6

Bohart-Adams and Wolborska model parameters

\begin{tabular}{|c|c|c|c|c|c|c|}
\hline \multirow[t]{2}{*}{ Sorbent } & \multirow[t]{2}{*}{$\mathrm{Z}(\mathrm{mm})$} & \multirow[t]{2}{*}{ Equation by $\ln \left(C / C_{0}\right)$ versus $t$} & \multirow[t]{2}{*}{$\mathbf{R}^{2}$} & \multicolumn{2}{|l|}{ Bohart-Adams model } & \multirow{2}{*}{$\begin{array}{l}\text { Wolborska model } \\
B\left(\min ^{-1}\right)\end{array}$} \\
\hline & & & & $\mathrm{K}_{\mathrm{AB}}\left(10^{-5} \mathrm{~L} \cdot \mathrm{mg}^{-1} \cdot \mathrm{min}^{-1}\right)$ & $\mathrm{N}_{\mathrm{o}}\left(\mathrm{mg} \cdot \mathrm{L}^{-1}\right)$ & \\
\hline PNB & 10 & $y=0.0034 x-0.8032$ & 0.95 & 4.11 & 20582.58 & 0.85 \\
\hline PNB & 15 & $y=0.0033 x-1.1684$ & 0.96 & 3.99 & 20565.6 & 0.82 \\
\hline PNB & 20 & $y=0.0012 x-0.9482$ & 0.84 & 1.45 & 34422.61 & 0.50 \\
\hline PNZ & 10 & $y=0.0022 x-0.5791$ & 0.93 & 2.66 & 22934.33 & 0.61 \\
\hline PNZ & 15 & $y=0.0013 x-0.6224$ & 0.93 & 1.57 & 27809.3 & 0.44 \\
\hline PNZ & 20 & $y=0.0009 x-0.8018$ & 0.92 & 1.09 & 38810.45 & 0.42 \\
\hline
\end{tabular}

In the Thomas model summarized in Table 7, parameters were estimated from the linear plot $\ln \left[\left(\mathrm{C}_{\mathrm{o}} / \mathrm{C}\right)-1\right]$ versus $\mathrm{V}_{\text {eff }}$ at $\mathrm{Q}=1 \mathrm{~mL} \cdot \mathrm{min}^{-1}$. The column data was fitted within the breakthrough curves' $0.1<\mathrm{C} / \mathrm{C}_{0}<0.9$ regions. Results show that $\mathrm{K}_{\mathrm{TH}}$ increases and $\mathrm{q}_{\mathrm{o}}$ decrease with the decreased mass of sorbent.

Table 7

Thomas model parameters

\begin{tabular}{|c|c|c|c|c|c|}
\hline Sorbent & $\mathrm{m}(\mathrm{g})$ & Equation by $\ln \left[\left(C_{0} / C\right)-1\right]$ versus $V_{\text {eff }}$ & $\mathbf{R}^{2}$ & $\mathrm{~K}^{\mathrm{TH}}\left(10^{-5} \mathrm{~L} \cdot \mathrm{mg}^{-1} \cdot \mathrm{min}^{-1}\right)$ & $\mathrm{q}_{0}\left(\mathrm{mg} \cdot \mathrm{g}^{-1}\right)$ \\
\hline PNB & 0.41 & $y=-0.0143 x+0.7374$ & 0.92 & 17.3 & 10.41 \\
\hline PNB & 0.61 & $y=-0.0071 x+0.9376$ & 0.96 & 8.57 & 17.93 \\
\hline PNB & 0.82 & $y=-0.0069 x+1.2511$ & 0.82 & 8.33 & 18.31 \\
\hline PNZ & 0.73 & $y=-0.0075 x-0.1571$ & 0.95 & 9.06 & 2.38 \\
\hline PNZ & 1.09 & $y=-0.0067 x+0.3316$ & 0.91 & 8.09 & 3.76 \\
\hline PNZ & 1.45 & $y=-0.0059 x+1.2613$ & 0.82 & 7.13 & 12.21 \\
\hline
\end{tabular}

The Yoon-Nelson parameters were estimated by plotting $\ln \left[\mathrm{C} /\left(\mathrm{C}_{\mathrm{O}}-\mathrm{C}\right)\right]$ versus t. Table 8 shows constant rate values, $\mathrm{K}_{\mathrm{YN}}$, and time at $50 \%$ concentration, $\tau$. As the bed height increases, $\mathrm{K}_{\mathrm{YN}}$ decreases while $\mathrm{t}$ increases.

Table 8

Yoon-Nelson model parameters

\begin{tabular}{|llllll|}
\hline Sorbent & $Z(\mathrm{~mm})$ & Equation by $\ln \left[\mathrm{C} /\left(\mathrm{C}_{\mathrm{o}}-\mathrm{C}\right)\right] \mathbf{v s}$ & $\mathbf{R}^{2}$ & $\mathrm{~K}_{\mathrm{YN}}\left(\mathrm{min}^{-1}\right)$ & $\tau(\mathrm{min})$ \\
\hline PNB & 10 & $\mathrm{y}=0.0143 \mathrm{x}-0.7374$ & 0.92 & 0.0143 & 65.57 \\
\hline PNB & 15 & $\mathrm{y}=0.0071 \mathrm{x}-0.9376$ & 0.96 & 0.0071 & 132.06 \\
\hline PNB & 20 & $\mathrm{y}=0.0069 \mathrm{x}-1.2511$ & 0.82 & 0.0069 & 181.32 \\
\hline PNZ & 10 & $\mathrm{y}=0.0075 \mathrm{x}+0.1571$ & 0.95 & 0.0075 & 20.95 \\
\hline PNZ & 15 & $\mathrm{y}=0.0067 \mathrm{x}-0.3316$ & 0.91 & 0.0067 & 49.49 \\
\hline PNZ & 20 & $\mathrm{y}=0.0059 \mathrm{x}-1.2613$ & 0.82 & 0.0059 & 213.7797 \\
\hline
\end{tabular}

The fit of the non-linear models and the actual plot of $\mathrm{C} / \mathrm{C}_{0}$ versus time are shown in Fig. 3 Column systems, and its parameters are summarized in Table 9 $\left(\mathrm{Q}=10 \mathrm{~mL} \cdot \mathrm{min}^{-1}\right)$. The Bohart-Adams and the Wolborska models follow the same upward curve for each system, while the Thomas model follows a downward curve. These three models have y-intercept values greater than zero. The Yoon-Nelson model closely follows the actual plot of $\mathrm{C} / \mathrm{C}_{0}$ versus time, including an estimated curve beginning from $\mathrm{t}=0$. The different adsorption models obtained provide valuable information for assessing the movement or the retention of metal ions from the liquid phase to the solid phase. Each column system may now be described by a specific adsorption model whose characteristic parameters be used in replicating the desired column behavior based on a chosen model. The information from the models is significant for the reproduction, scaling up, and improvement of a column system. 
Table 9

Non-linear sorption models

\begin{tabular}{|c|c|c|c|c|c|c|c|c|}
\hline SYSTEM & Sorbent & Z, & Bohart-Adams & Thomas & & Yoon- & elson & \\
\hline A & PNB & 10 & $\frac{C}{C_{o}}=\exp [0.0034 t-0.8032]$ & $\frac{C}{C_{o}}=$ & $\frac{1}{1+\exp [0.73474-0.0143 t]}$ & $\frac{C}{C_{o}}=$ & {$[1-$} & $\frac{\left(C_{O^{-}}-C\right) \exp \frac{0.73474-0.0143 t]}{C_{O}}}{}$ \\
\hline B & & 15 & $\frac{C}{C_{o}}=\exp [0.0033 t-1.1684]$ & $\frac{C}{C_{o}}=$ & $\frac{1}{1+\exp [0.9376-0.0071 t]}$ & $\frac{C}{C_{o}}=$ & {$[1-$} & 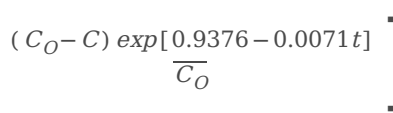 \\
\hline C & & 20 & $\frac{C}{C_{o}}=\exp [0.0012 t-0.9482]$ & $\frac{C}{C_{o}}=$ & $\frac{1}{1+\exp [1.2511-0.0069 t]}$ & $\frac{C}{C_{o}}=$ & {$[1-$} & $\frac{\left(C_{O}-C\right) \exp \left[\frac{1.2511}{C_{O}}-0.00693 t\right]}{2}$ \\
\hline $\mathrm{D}$ & PNZ & 10 & $\frac{C}{C_{o}}=\exp [0.0022 t-0.5791]$ & $\frac{C}{C_{o}}=$ & $\frac{1}{1+\exp [0.1571-0.0075 t]}$ & $\frac{C}{C_{o}}=$ & {$[1-$} & $\left(C_{O^{-}}-C\right) \exp \frac{0.1571-0.0059 t]}{C_{O}}$ \\
\hline $\mathrm{E}$ & & 15 & $\frac{C}{C_{o}}=\exp [0.0013 t-0.6224]$ & $\frac{C}{C_{o}}=$ & $\frac{1}{1+\exp [0.3316-0.0067 t]}$ & $\frac{C}{C_{o}}=$ & {$[1-$} & 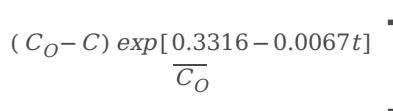 \\
\hline $\mathrm{F}$ & & 20 & $\frac{C}{C_{o}}=\exp [0.0009 t-0.8018]$ & $\frac{C}{C_{o}}=$ & $\frac{1}{1+\exp [1.2613-0.0059 t]}$ & $\frac{C}{C_{o}}=$ & {$[1-$} & $\frac{\left.\left(C_{O}-C\right) \exp \frac{[1.2613}{C_{O}}-0.0059 t\right]}{2}$ \\
\hline
\end{tabular}

\subsection{Effect of varying flow rate}

The results of varying the flow rate from $1 \mathrm{~mL} \cdot \mathrm{min}^{-1}$ to $3 \mathrm{~mL} \cdot \mathrm{min}^{-1}$ on both PNB and PNZ sorbents with a constant bed height of $10 \mathrm{~mm}$ are shown in Fig. 4 . In this result, increasing the flow rate leads to a faster uptake (lesser saturation time) of both sorbents at $90 \%$ of the initial concentration. The plot of each sorbent in an increased flowrate is moving upward, resulting in a smaller area above the curve which translates into lower uptake capacity. This is explained by the accelerated movement of $\mathrm{Pb}$ in the system resulted in less sufficient residency time in the column. These results agree with the study by Chittoo and Sutherland (2020), where increased flow rates resulted in lessened contact time between the sorbent and sorbate.

\subsection{Effect of bed height}

Figure 5 below shows the effect of bed height relative to dynamic uptake capacity, saturation time, and removal percentage. The bed height of the columns was varied at $10 \mathrm{~mm}, 15 \mathrm{~mm}$, and $20 \mathrm{~mm}$ for both PNB and PNZ sorbents with a constant flow rate at $1 \mathrm{~mL} \cdot \mathrm{min}^{-1}$. Results showed that increasing the bed height yielded a more uptake capacity, saturation time at $\mathrm{C} / \mathrm{Co}=90 \%$, and removal percentage against $\mathrm{Pb}$. These results coincide with the adsorption study by Zhang et al. (2019), where the increase of bed height resulted in a slower breakthrough that translates into higher saturation time. The gradual addition of sorbent in an increased bed height supports the idea that it takes longer to saturate the sorbent thoroughly. Hence, an increased amount of sorbent will have more adsorption sites available, resulting in capacity uptake improvement and a higher removal percentage of lead in the system.

\subsection{Cost-efficiencies}

The prices of the sorbents per kilogram are 17.5 Philippine peso (PHP) for PNB and 16.5 pesos for PNZ. The cost-efficiencies of each sorbent as cost per amount of $\mathrm{Pb}$ removed (PHP/g Pb) were calculated using the mass of $\mathrm{Pb}$ adsorbed per mass of adsorbent as summarized in Table 10. Results show that PNB can remove a gram of lead 2.17 PHP cheaper than PNZ. A unit of PNB is more expensive than a unit of PNZ; however, PNB removes a gram of lead for a much more affordable price than PNZ.

Table 10

Cost and cost efficiencies of PNB and PNZ

\begin{tabular}{|llll|}
\hline Sorbent & PHP/kg & $q_{e, a v e}$ (g Pb/g sorbent) & PHP / g Pb \\
\hline PNB & 17.50 & 0.031 & 1.13 \\
PNZ & 16.5 & 0.010 & 3.30 \\
\hline
\end{tabular}

\section{Conclusions And Recommendations}

This study was carried out to evaluate and compare the utilization of PNZ and PNB sorbents in removing potentially toxic chemicals in the wastewater from small-scale mines. The wastewater from the ball mill facilities contained average heavy metal concentrations of $82.8 \mathrm{ppm}, 19 \mathrm{ppm}$, and $432.4 \mathrm{ppm}$ for Pb, $\mathrm{Cd}$, and Fe, respectively. Column studies were conducted to evaluate the adsorption performance of the PNZ and PNB against Pb at varied flow rates and bed heights. Key findings of the study showed that PNB is a better adsorbent against heavy metals due to a lower experimental Si/Al ratio than PNZ. This is 
confirmed by comparing the removal percentages of the two sorbents in terms of $\mathrm{Pb}$ removal. The removal percentage of $\mathrm{PNB}$ was $50.43 \%$ which is significantly greater than PNZ with $26.90 \%$. The significant difference between PNB and PNZ was further confirmed by determining the dynamic uptake capacity and maximum adsorption capacity, wherein PNB yields higher values than PNZ. In applying empirical sorption models, the Yoon-Nelson model visually shows the closest estimation of actual values; however, the curves produced are not smooth.

Nevertheless, the effect of flow rate for the two sorbents showed that an increase in flow rate results in a lesser saturation time at $90 \%$ initial concentration. Meaning, the faster the inlet flow rate, the higher it takes for the sorbent to be spent. Moreover, varying the bed height of the columns showed that the more bed height, the higher the uptake capacity, saturation time, and removal percentage for both sorbents. Furthermore, in terms of the cost-efficiencies of the sorbents, it revealed that PNB could remove a gram of lead 2.17PHP cheaper than PNZ; thus, PNB is more cost-efficient. To further investigate the adsorption performance of the PNB and PNZ sorbents, it is recommended to study the effect of sorbent particle sizes on the adsorption capacity. Additionally, the study only investigates the sorption properties of virgin PNB and PNZ sorbent. It is recommended to study the reusability of the sorbents after exhaustion. Regeneration studies to minimize the demand for virgin sorbents, reduce secondary pollution, and address the disposal problem.

\section{Declarations}

\section{Acknowledgment}

The Department of Science and Technology Science Education Institute (DOST-SEI) provides funding for this research under the Science and Technology Regional Alliance of Universities for Inclusive Development (Strand) scholarship.

\section{Ethics approval and consent to participate}

Not applicable.

\section{Consent to publication}

Not applicable.

\section{Funding}

This work was supported by the Department of Science and Technology Science Education Institute (DOST-SEI) under the Science and Technology Regional Alliance of Universities for Inclusive Development (Strand) scholarship.

\section{Competing Interests}

The authors have no relevant financial or non-financial interests to disclose.

\section{Authors Contribution}

All authors contributed to the study. Material preparation, data collection and analysis were performed by Jyra Rancel Banta. The first draft of the manuscript was edited and approved by Marcelino Lunag Jr. All authors read and approved the final manuscript.

\section{Availability of Data and Materials}

Not applicable.

\section{References}

1. Acheampong MA, Meulepas RJW, Lens PNL (2010) Removal of heavy metals and cyanide from gold mine wastewater. J Chem Technol Biotechnol 85:590-613. https://doi.org/10.1002/jctb.2358

2. Bohart GS, Adams EQ (1920) Some Aspects of the Behavior of. Charcoal With Respect to Chlorine

3. Chittoo BS, Sutherland C (2020) Column breakthrough studies for the removal and recovery of phosphate by lime-iron sludge: Modeling and optimization using artificial neural network and adaptive neuro-fuzzy inference system. Chinese Journal of Chemical Engineering 28:1847-1859. https://doi.org/10.1016/j.cjche.2020.02.022

4. DENR (2016) Water Quality Guidelines and General Effluent Standards of 2016. DENR Administrative Order 2016-08

5. Gili MB, Olegario-Sanchez L, Conato M (2019) Adsorption uptake of Philippine natural zeolite for Zn 2+ ions in aqueous solution. Journal of Physics: Conference Series 1191:12042. https://doi.org/10.1088/1742-6596/1191/1/012042

6. Gili MBZ, Hila FC (2021) Characterization and Radiation Shielding Properties of Philippine Natural Bentonite and Zeolite. Philippine Journal of Science 150:1475-1488

7. Karimi M, Shojaei A, Nematollahzadeh A, Abdekhodaie MJ (2012) Column study of $\mathrm{Cr}(\mathrm{VI})$ adsorption onto modified silica-polyacrylamide microspheres composite. Chem Eng J 210:280-288. https://doi.org/10.1016/j.cej.2012.08.046 
8. Macasieb RQ, Tapales BJM, Orozco CR, Resurreccion AC (2014) Characterization and Heavy Metal Contamination Assessment of Sediments in Bued River. 11th Engineering Research and Development for Technology Conference, UP Diliman, Philippines

9. Mendoza HD (2014) ECO-FRIENDLY Recovery of GOLD and COPPER. for the Small-Scale Mining Industry

10. Olegario EM, Gili MBZ (2021) Characterization of Philippine natural bentonite. Experimental Results 2:1-10. https://doi.org/10.1017/exp.2021.16

11. Olegario-Sanchez E, Pelicano CM (2017) Characterization of Philippine Natural Zeolite and its Application for Heavy Metal Removal from Acid Mine Drainage (AMD). Key Eng Mater 737:407-411. https://doi.org/10.4028/www.scientific.net/KEM.737.407

12. PSA (2013) Mines and Minerals: Philippine Yearbook 2011

13. Rashotte N (2019) Mining for Gold in the Philippines. Gold Mining Companies

14. Sazali N, Harun Z, Sazali N (2020) A Review on Batch and Column Adsorption of Various Adsorbent Towards the Removal of Heavy Metal. Journal of Advanced Research in Fluid Mechanics and Thermal Sciences Journal homepage 67:66-88

15. Simeon LM (2019) Mining group renews call for crackdown on small-scale operations. The Philippione Star

16. Trgo M, Vukojević Medvidović N, Perić J (2011) Application of mathematical empirical models to dynamic removal of lead on natural zeolite clinoptilolite in a fixed bed column

17. Uddin MK (2017) A review on the adsorption of heavy metals by clay minerals, with special focus on the past decade. Chem Eng J 308:438-462. https://doi.org/10.1016/j.cej.2016.09.029

18. Wolborska A (1989) ADSORPTION ON ACTIVATED CARBON OF p-NITROPHENOL. FROM AQUEOUS SOLUTION

19. Zhang Y, Jin F, Shen Z et al (2019) Adsorption of methyl tert-butyl ether (MTBE) onto ZSM-5 zeolite: Fixed-bed column tests, breakthrough curve modelling and regeneration. Chemosphere 220:422-431. https://doi.org/10.1016/j.chemosphere.2018.12.170

20. Zhou S, Yuan Z, Cheng Q et al (2018) Rapid in situ determination of heavy metal concentrations in polluted water via portable XRF: Using Cu and Pb as example. Environmental pollution (Barking, Essex: 1987) 243:1325-1333. https://doi.org/10.1016/j.envpol.2018.09.087

\section{Figures}

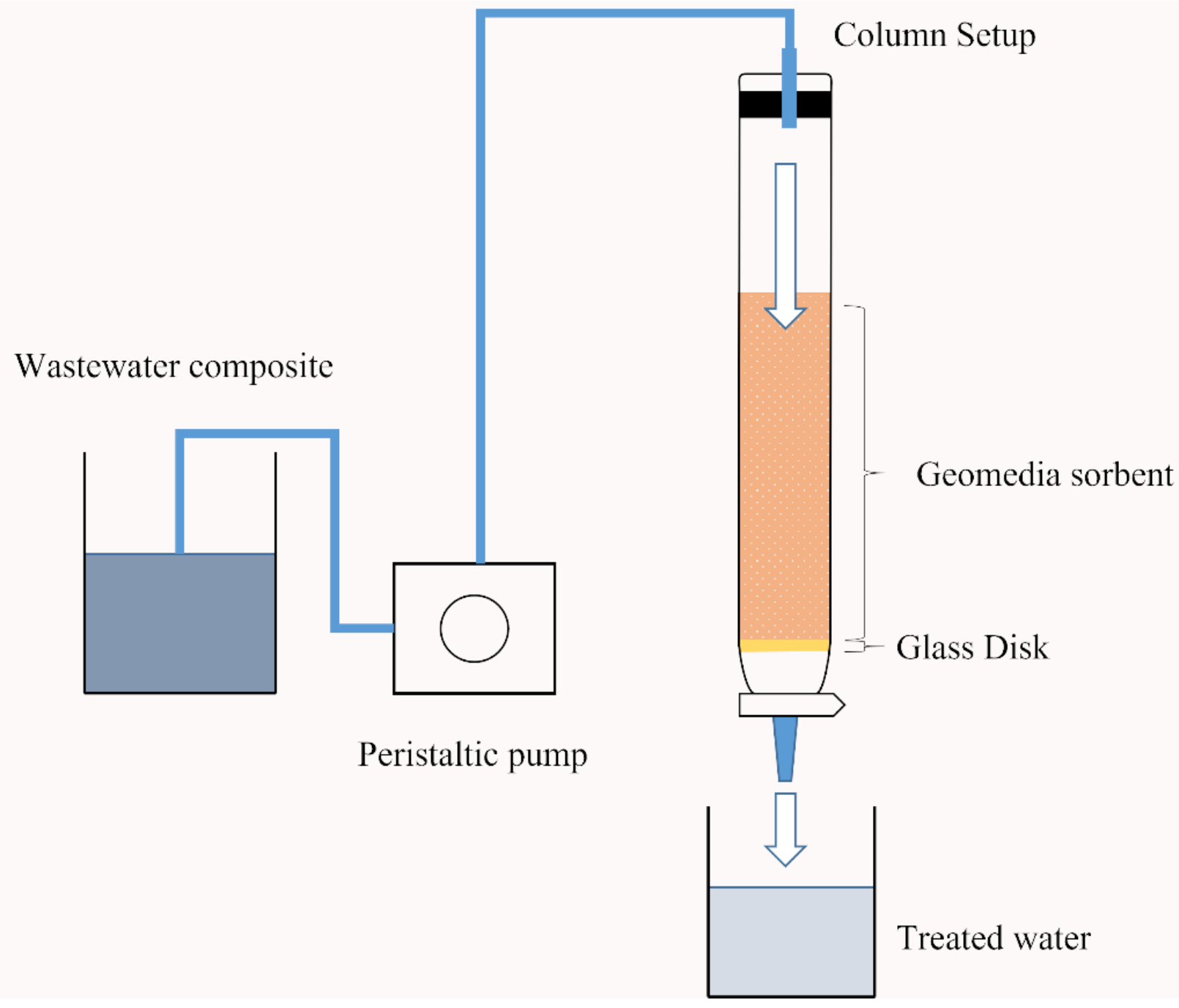

Figure 1

Page $11 / 14$ 

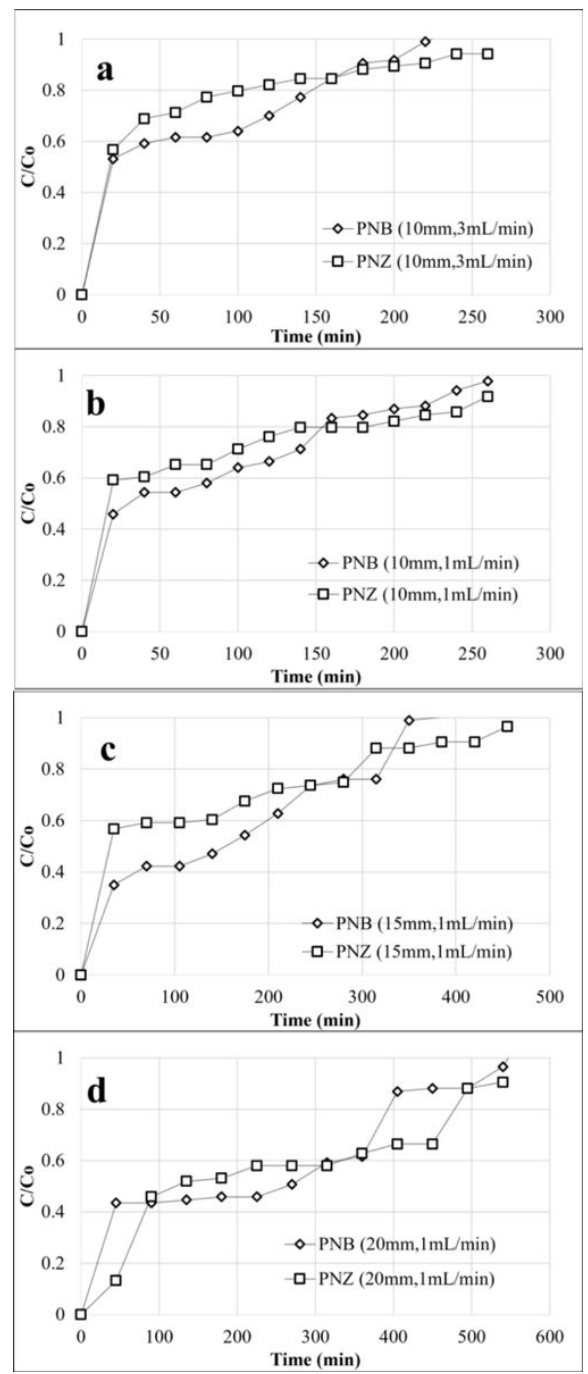

\section{Figure 2}

Breakthrough curves of lead adsorption of PNZ and PNB (a) Z=10mm, Q=3mL $\cdot \mathrm{min}^{-1}$, (b) $Z=10 \mathrm{~mm}, Q=1 \mathrm{~mL} \cdot \mathrm{min}^{-1}$, (c) $Z=15 \mathrm{~mm}, Q=1 \mathrm{~mL} \cdot \mathrm{min}^{-1}$, and (d) $\mathrm{Z}=20 \mathrm{~mm}, \mathrm{Q}=1 \mathrm{~mL} \cdot \mathrm{min}^{-1}$ 

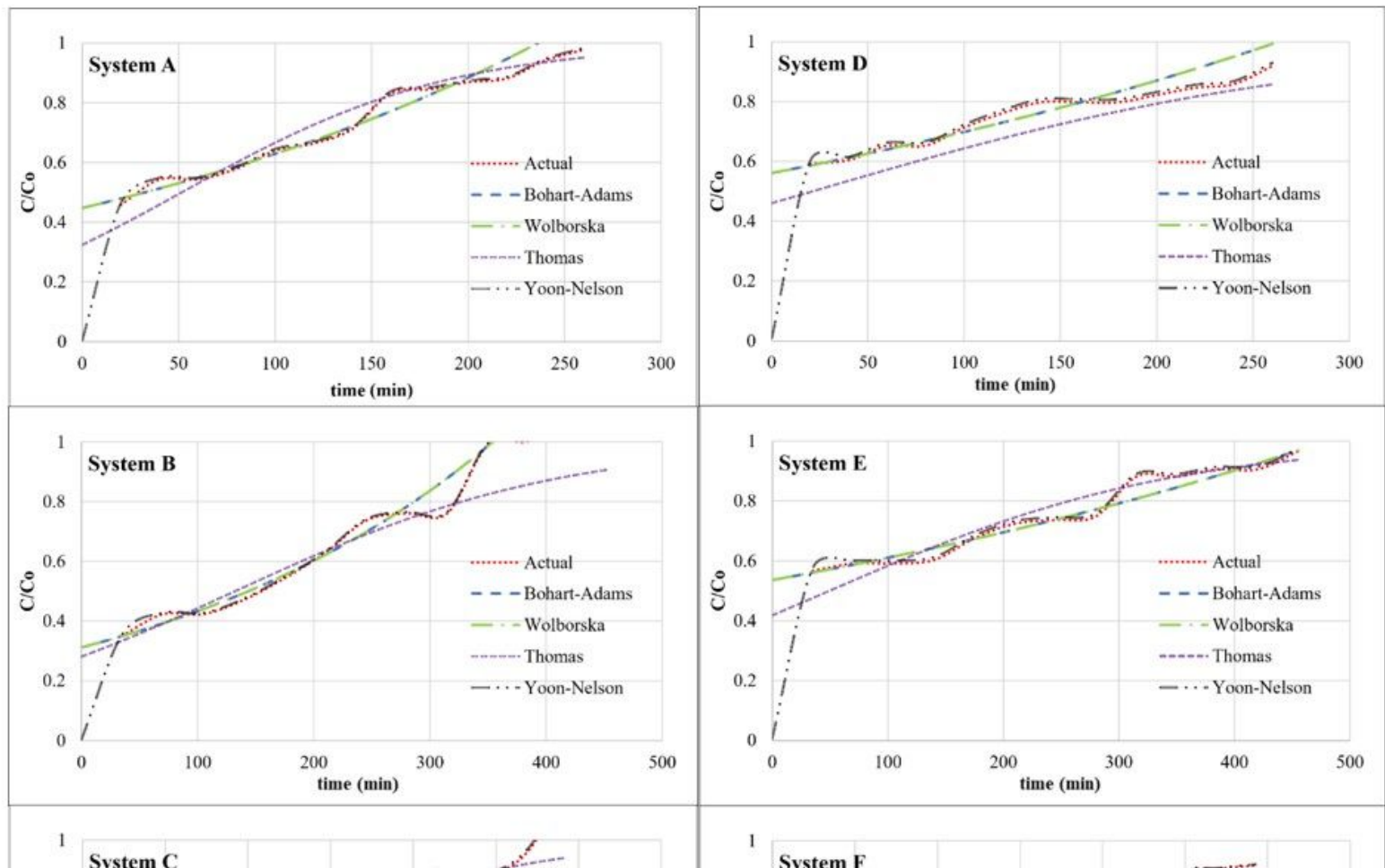

Figure 3

Actual and mathematical breakthrough curves of (a) Systems A-C and (b) Systems D-F 


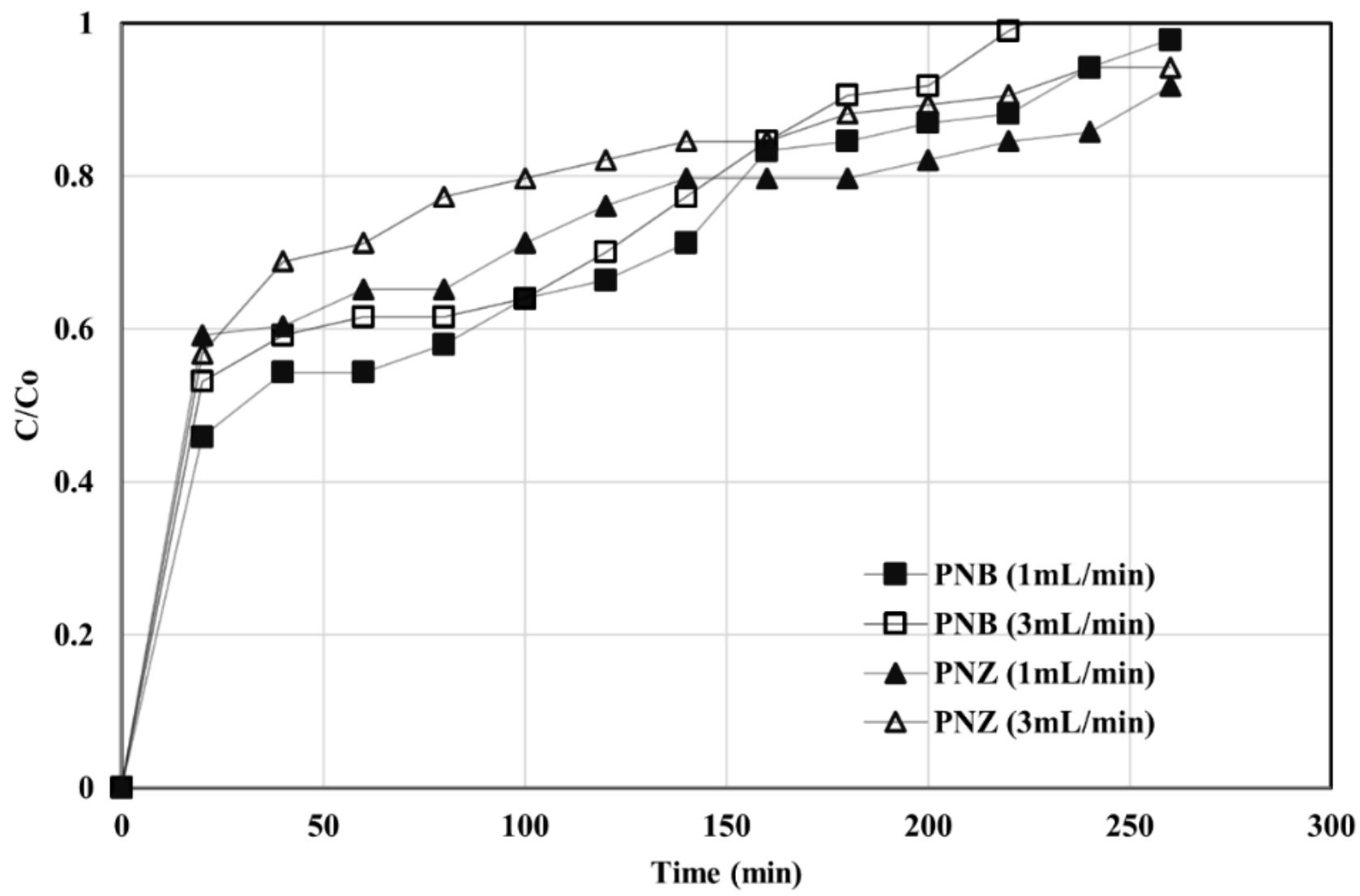

Figure 4

Breakthrough curves at a varied flowrate

Figure 5

Effect of bed height to (a) dynamic uptake capacity, (b) saturation time at $C / C_{0}=90 \%$, and (c) removal percentage 